MARINE MAMMAL SCIENCE, 30(4): 1417-1426 (October 2014)

(C) 2014 Society for Marine Mammalogy

DOI: $10.1111 / \mathrm{mms} .12125$

\title{
Changes in the acoustic behavior of resident bottlenose dolphins near operating vessels
}

\author{
Ana Rita Luís, ${ }^{1}$ Miguel N. Couchinho and Manuel E. dos Santos, Eco-Ethology \\ Research Unit, ISPA-Instituto Universitário, Rua Jardim do Tabaco, 34, Lisboa, P-1149-041, \\ Portugal and Projecto Delfim-Centro Português de Estudo dos Mamíferos Marinhos, Rua Alto \\ do Duque, 45, Lisboa, P-1400-009, Portugal.
}

\begin{abstract}
Maritime traffic is an issue of major ecological concern, and vessel noise may be an important source of disturbance for coastal cetaceans. In the Sado estuary, Portugal, core habitat areas of a small resident population of bottlenose dolphins (Tursiops truncatus) overlap with routes of intense maritime traffic, which presents an opportunity to assess vocal responses of these dolphins to specific vessel noise sources. Field recordings of dolphin vocalizations were made from April to November 2011, using a calibrated system. Dolphin behavior and group size were recorded, as well as the operating boat condition (no boats or specific boat type) in a $1,000 \mathrm{~m}$ radius. Spectral analyses of vocalizations allowed the categorization and quantitative analysis of echolocation click trains and social calls, including whistles. Mean overall call rates decreased significantly in the presence of operating vessels. Creaks (fast click trains) were significantly reduced in the presence of ferry boats. Significant differences were also observed in the whistles' minimum, maximum, and start frequencies. These changes in call emission rates and temporary shifts in whistles characteristics may be a vocal response to the proximity of operating vessels, facilitating communication in this busy, noisy estuary.
\end{abstract}

Key words: Tursiops truncatus, bottlenose dolphin, acoustic behavior, maritime traffic, underwater noise.

Much concern has been expressed about the effects of man-made noise on marine life (see Popper and Hawkins 2012). Notable efforts have been made to document, demonstrate, measure, or estimate the extent of such effects, namely on aquatic mammals (e.g., Nowacek et al. 2007), especially considering that sound is important for these animals in finding prey (Au 1993), avoiding predators (Deecke et al. 2005), and communicating with conspecifics (Tyack 1998).

In line with current risk-assessment criteria, recent European Union documents (Tasker et al. 2010, Van der Graaf et al. 2012, Dekeling et al. 2013) highlight the importance of ambient noise monitoring, and studies of behavioral responses to specific noise sources. Some threats are considered more immediately deleterious, such as underwater explosions, air guns used in oil exploration, and mid-frequency military sonars (Hatch and Wright 2007, Hildebrand 2009, dos Santos et al. 2010, Dolman et al. 2011, Goldbogen et al. 2013). Acoustic deterrent devices and shipping

\footnotetext{
${ }^{1}$ Corresponding author (e-mail: aluis@ispa.pt).
} 
noise are more chronic and pervasive, and have also been studied for their potential impacts on marine mammals (Aguilar de Soto et al. 2006, Leeney et al. 2007, Hildebrand 2009).

Maritime traffic is indeed a heavy contributor to the increasing levels of noise in the oceans (Richardson et al. 1995), and it is considered the main contributor to the rise in background noise in European waters (Tasker et al. 2010). This issue is of particular concern in coastal areas, where vessel noise may be an important source of disturbance for cetaceans, especially in the case of local, resident populations.

Several studies have reported short-term behavioral responses of bottlenose dolphin schools to boat traffic, namely increases in group cohesion, dive duration, and traveling behavior (Nowacek et al. 2001, Miller et al. 2008); changes in breathing and surfacing patterns (Janik and Thompson 1996, Hastie et al. 2003); and reduction of aerial behaviors and cessation of feeding, social, and resting events (Papale et al. 2012). Nevertheless, the effects of vessel noise on the acoustic behavior of cetaceans, especially in the case of resident populations, are still poorly documented.

Studies on the acoustic behavior of bottlenose dolphins when in the presence of vessels focus mainly, on the emission of whistles. Although, increases in whistling rate have been reported (Scarpaci et al. 2000, Buckstaff 2004), changes in the acoustic behavior to the presence of vessels do not always occur (Lemon et al. 2006).

Delphinids appear to have differential responses to vessel noise. For example, Lesage et al. (1999) revealed that belugas reduced their overall call rate in the presence of vessels, but increased the emission and repetition of specific calls and shifted to higher frequency bands. Increases in the duration and source level of killer whale calls have been documented in the presence of boats (Foote et al. 2004, Holt et al. 2008) and Van Parijs and Corkeron (2001) reported increases in the whistling rate at a boat's passage but no changes in emission rates of click trains and burst pulses of Sousa chinensis. Jensen et al. (2009) estimated that vessels within a $50 \mathrm{~m}$ radius could cause a reduction of $26 \%$ in the communication range of bottlenose dolphins in shallow waters but the biological implications are still scarcely documented.

In the Sado estuary (Portugal), a small resident population of approximately 28 common bottlenose dolphins (Augusto et al. 2012) is exposed to vessel noise on a daily basis. Core dolphin habitat overlaps with zones of high maritime traffic, which presents an opportunity to assess the vocal responses of dolphins to specific noise sources. In the present study, we investigate the acoustic behavior of bottlenose dolphins in the absence and presence of different types of vessels. Specifically we examined overall call rates, whistle characteristics, and whether changes in the various burst-pulsed emissions occur in relation to boat traffic.

\section{Methods}

Field recordings were made in the Sado estuary, Portugal, and adjacent coastal waters (Fig. 1). All data were collected from an $8.40 \mathrm{~m}$ inboard motor vessel during daylight hours (1000-1800), on 32 d from April to November 2011, with sea state ranging from 0 to 2 Beaufort. Whenever a group of dolphins was detected, the research vessel was positioned approximately $500 \mathrm{~m}$ ahead of the group's displacement, with the engines off, and the hydrophone placed at a depth of $3 \mathrm{~m}$. When 


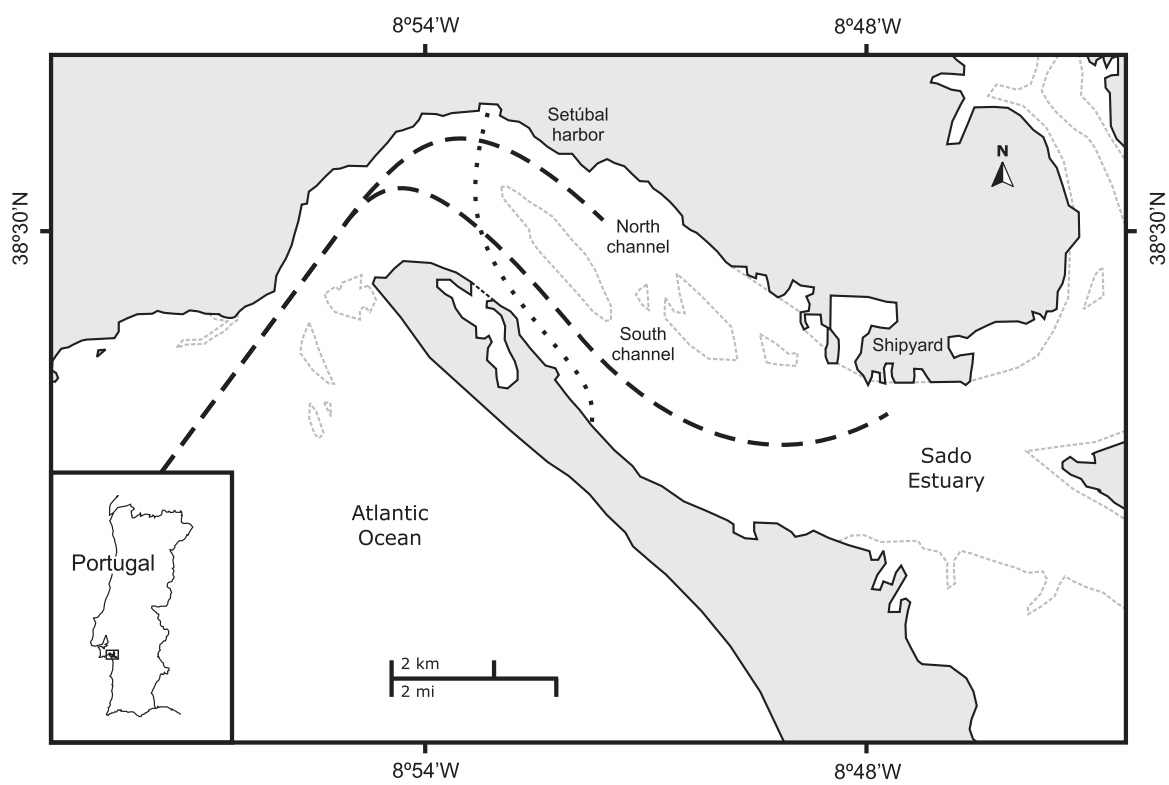

Figure 1. Map of study area in Sado estuary, Portugal. Ferry boat route is shown in black dashed line and ship channel is shown in black long dashed line.

vessels were operating within a 1,000 m radius, this was noted and vessel type categorized as "Tanker," "Cargo freighter," "Ferry boat," "Trawler," "Salt galleon" (traditional tour boats with sails), "Leisure boat" (with inboard engine), "Small boat" (with outboard engine), or "Dolphin-watching vessel Esperança." When no operating boats where present, "No boats" was noted.

All acoustic measurements were carried out using a factory-calibrated recording system: a Cetacean Research Technology hydrophone, model C55 (effective sensitivity of $-165 \mathrm{~dB}$ re $1 \mathrm{~V}=1 \mu \mathrm{Pa}$, frequency response of $\pm 3 \mathrm{~dB}$ in the $0.020-44 \mathrm{kHz}$ band and $+3 /-13 \mathrm{~dB}$ in the $0.009-100 \mathrm{kHz}$ band, polarized by a $9 \mathrm{~V}$ battery) connected by a 15 m cable to a Fostex FR-2 digital recorder. High-pass filter of $100 \mathrm{~Hz}$ was chosen to avoid self-noise generated by the recording platform and low-frequency vibrations. One-minute duration recordings were made, with a sampling rate of 192 $\mathrm{kHz}$ and 24 bit resolution, recording level at 7.5 and trim level at $-26 \mathrm{~dB}$. All recordings were stored on Compact Flash memory cards as time-stamped wave files. The geographic location of each recording was given by a Garmin Foretrex 301 portable GPS.

Behavioral context was ascribed according with the following categories (dos Santos et al. 2005): (1) travel-rapid, linear displacement of a tight group moving between areas, with no aerial behaviors; (2) foraging - zigzag displacement of a subdivided group, with dives longer than $1 \mathrm{~min}$ and occasional aerial activity or fish chase; (3) feeding - individual animals, dyads, or tryads surfacing more than $10 \mathrm{~m}$ apart, with only very short dives and abundant movements at the surface, including captures, prey leaping, or prey toss; and (4) socializing-dyads or tryads showing excited surface and aerial behaviors, with physical contacts and no prey detectable, sometimes with synchronous movements. Group size was determined by direct counting of the animals by two observers, averaging the counts. 
Acoustic Analyses

Recordings were first inspected by two trained independent observers, aurally and visually, using Adobe Audition CS5.5 (Adobe Systems Inc., San Jose, CA) with Hamming windows of 512 points, in order to identify, categorize, and count all the vocal elements present in each sample.

Vocal elements were classified and counted in each sample. For slow click trains (repetition rate $<40 \mathrm{clicks} / \mathrm{s}$ ), presumably with a general echolocation function ( $\mathrm{Au}$ 1993), the number of individual clicks was determined. For fast, indiscernible click trains (burst-pulses), three categories were created according to repetition rate and duration: "Creaks" $(>0.2$ s duration, 40-200 clicks/s); "Squawks" $(>0.2$ s duration, 200-600 clicks/s) and "Buzzes" ( $<0.2$ s duration, 200-400 clicks/s). Other pulsed sounds were categorized as "Bangs," broadband impulsive sounds; "Gulps," low-frequency impulsive sounds; "Squeaks," short pulsed calls that sound tonal to the human ear; and "Grunts," broadband burst pulses, with strong emphasis in the lower frequencies. Tonal, narrow-band, modulated signals were classified as "Whistles." The analysis of burst-pulses, other pulsed sounds and whistles was based on the number of recognizable units.

To estimate the number of clicks per sample, the interactive detection function of Raven Pro 1.4 (Cornell Lab of Ornithology, Ithaca, NY) was used (also with Hamming windows of 512 points). Detection function parameters were adjusted to each file individually in order to optimize the signal-to-noise ratio and, subsequently, the detection probability in each recording. Detections were validated by a trained observer.

Raven Pro 1.4 was used to measure the acoustic parameters of previously selected whistles: start frequency, end frequency, minimum frequency, maximum frequency, and duration.

\section{Statistical Analyses}

As the abundance of emissions could be a direct function of group size, this variable had to be analyzed. To do so, correlations were calculated between group size and the mean count of each vocal element (Pearson product-moment correlation, Gravetter and Wallnau 2000).

Analysis of variance (one-way ANOVA) was used to assess the differences in the mean call rate according to operating boat condition. Contrast analysis was used to test whether the presence of vessels could account for significant differences in the mean overall call rate. Tukey post hoc test was performed for pairwise comparisons. Due to their specific metrics and wide variance of occurrence, clicks were not included in the call rate analysis.

Analyses of variance were performed, individually, for the following vocal elements (one-way ANOVA, with Welch correction when necessary): Whistles, Creaks, Squawks, Squeaks, and Clicks, using Bonferroni correction (significance level $=0.01$ ). Several acoustic parameters of whistles (start frequency, end frequency, minimum frequency, maximum frequency, and duration) were also analyzed using a series of one-way ANOVAs, using Bonferroni correction (significance level $=0.01$ ). Tukey HSD and Dunnet's T3 post hoc tests were performed for pairwise comparisons. All statistical analyses were performed using IBM SPSS Statistics 21 (IBM Inc.) 


\section{RESULTS}

A total of 205 samples recorded within the study area were selected for analysis (ferry boats $=24$, trawlers $=12$, leisure boats $=16$ and dolphin-watching vessel $=18$, no boats $=135)$. Operating boat types with fewer than 10 cases were excluded from analyses.

No correlations were found between dolphin group size and the mean overall number of vocal elements recorded in each sample $(r=0.013, P=0.853)$. Therefore, group size was not included in the analysis of variance of vocal elements and acoustic parameters.

The analyses performed to assess the variance in the call rate for each boat type revealed no significant differences among the groups $\left(F_{4,200}=1.729, P=0.145\right)$. Nevertheless, the contrast test revealed that, in the presence of operating vessels, the mean call rate diminished significantly $\left(t_{200}=2.172, P=0.031\right)$. For the category "Ferry boat" the mean call rate was of only seven calls per minute, which is significantly lower $(P=0.023)$ than the 22 vocalizations recorded per minute in the absence of boats (Fig. 2).

The analysis of variance performed for each vocal element revealed that only the mean number of creaks differed significantly according to the operating boat type $\left(F_{\text {Welch 4, 40.985 }}=5.037, P=0.002\right)$. For the categories "Ferry boat" and "Dolphinwatching vessel" the mean number of creaks recorded per minute was considerably lower than the mean number of creaks recorded in the absence of boats $(P=0.01$ and $\left.P=0.015^{*}\right)-1.2$ and 1.4 vs. 3.5 per minute (Fig. 3). The mean number of whistles, squawks, squeaks, and clicks did not differ significantly between the analyzed conditions. Although not included in the analyses of variance, it should be pointed out that no "Gulps" or "Grunts" were recorded in the presence of trawlers during this study. "Bangs" were not recorded in the presence of trawlers or ferry boats and "Buzzes" were not recorded in the presence of ferry boats or leisure boats.

Based on recording quality and signal-to-noise ratio, a total of 570 whistles from the various conditions were selected for acoustic parameter analysis (ferry boats $=33$, trawlers $=31$, leisure boats $=37$ and dolphin-watching vessel $=56$, no boats $=413$ ).

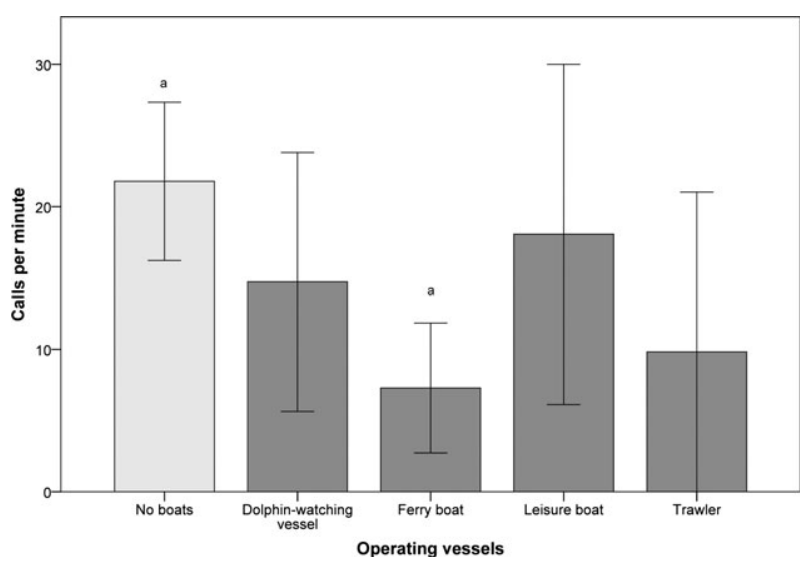

Figure 2. Calls per minute by type of operating vessel. Error bars 95\% CI. Significant differences: $\mathrm{a}=$ no active vessel $v$. ferry boat. 


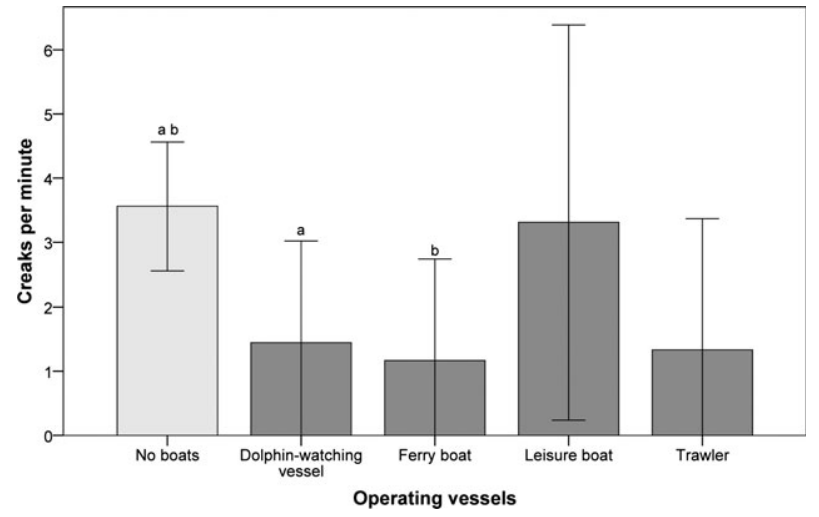

Figure 3. Creaks per minute by type of operating vessel. Error bars $99 \%$ CI. Significant differences: $\mathrm{a}=$ no active vessel $v$ s. dolphin-watching vessel $\left(P=0.015^{*}\right.$, marginal significance); $\mathrm{b}=$ no active vessel $v$ s. ferry boat $(P=0.010)$.

Table 1. Mean values of whistles' acoustic parameters for each category of operating boat.

\begin{tabular}{lccccc}
\hline \hline & $\begin{array}{c}\text { Start } \\
\text { frequency } \\
(\mathrm{kHz})\end{array}$ & $\begin{array}{c}\text { End } \\
\text { frequency } \\
(\mathrm{kHz})\end{array}$ & $\begin{array}{c}\text { Minimum } \\
\text { frequency } \\
(\mathrm{kHz})\end{array}$ & $\begin{array}{c}\text { Maximum } \\
\text { frequency } \\
(\mathrm{kHz})\end{array}$ & $\begin{array}{c}\text { Duration } \\
(\mathrm{s})\end{array}$ \\
\hline No boats & $7.57^{\mathrm{ac}}$ & 11.07 & $6.71^{\mathrm{a}}$ & 14.21 & 0.71 \\
Dolphin-watching & 7.98 & 11.11 & 6.99 & $15.33^{\mathrm{a}}$ & 0.82 \\
Ferry boat & $10.52^{\mathrm{ab}}$ & 9.97 & $8.49^{\mathrm{ab}}$ & 13.72 & 0.49 \\
Leisure boat & $10.37^{\mathrm{cd}}$ & 10.74 & 8.10 & 14.70 & 0.59 \\
Trawler & $6.60^{\mathrm{bd}}$ & 9.55 & $6.25^{\mathrm{b}}$ & $12.46^{\mathrm{a}}$ & 0.75 \\
\hline
\end{tabular}

Note: Significant differences in bold, with letters indicating the pairwise comparison results. Significance level of 0.01 .

Significant differences were found for the minimum and maximum frequencies of the whistles among the various conditions $\left(F_{4,570}=6.121, P<0.001 ; F_{4,570}=3.808\right.$, $P=0.005)$. Post boc Tukey HSD tests revealed significant differences in the minimum frequency between the "Ferry boats" $(8.49 \mathrm{kHz})$, and "No boats" $(6.71 \mathrm{kHz})$ and "Trawler" $(6.25 \mathrm{kHz})$. For maximum frequency, significant differences were found between the dolphin-watching boat $(15.33 \mathrm{kHz})$ and the trawlers $(12.46 \mathrm{kHz})$ (Table 1).

Significant differences among vessel categories were also found for the start frequency $\left(F_{4,570}=10.759, P<0.001\right)$. Post hoc Tukey HSD tests revealed significant differences between "Ferry boats" $(10.52 \mathrm{kHz})$, and "No boats" $(7.57 \mathrm{kHz})$ and "Trawler" $(6.60 \mathrm{kHz})$ and between "Leisure boats" $(10.52 \mathrm{kHz})$ and "No boats" and "Trawler" (Table 1).

\section{Discussion}

In this study, the acoustic behavior of bottlenose dolphins resident in the Sado region was sampled in the absence of nearby boats and in the proximity of various types of vessels. Several species of animals, including bottlenose dolphins, are known 
to adjust their acoustic behavior in order to reduce noise masking, by changing call emission rates and/or by shifting the acoustic frequency of vocal elements (Lesage et al. 1999, Scarpaci et al. 2000, Van Parijs and Corkeron 2001, Buckstaff 2004, Brumm and Slabbekoorn 2005). Evidence for both responses is presented in this study: changes in the call rates and whistle characteristics were statistically significant in the presence of certain vessels.

Overall call rate was lower in the presence of operating vessels, especially ferry boats. Reducing overall emission rates is a common response of marine mammals to noise (Weilgart 2007), perhaps to optimize communication efficiency or as an alertness response. Bird species that inhabit urban areas, with high levels of anthropogenic noise, are known to decrease singing during the noisiest periods (daytime), in order to take advantage of temporal variations in ambient noise (Fuller et al. 2007). Similarly, and since ferry boat noise is a regular, even predictable, variable on a specific section of the Sado estuary, dolphins may adjust their call rates temporally, avoiding the noisiest periods.

The decrease in the emission rate of specific vocalizations may have important biological implications depending on the calls that are affected (Weilgart 2007). In the presence of ferry boats and the dolphin-watching boat studied, dolphins reduced their emission of creak burst-pulses associated with detailed echolocation, especially in foraging and feeding events (Herzing 1996, Miller et al. 2004). Similar results have been observed in sperm whales (Physeter macrocephalus) in response to airgun sound exposure (IWC 2008, Tyack 2009) and in Cuvier's beaked whales (Ziphius cavirostris) as a response to ship noise (Aguilar de Soto et al. 2006). In bats, another sonar-dependent predator, foraging efficiency decreases in the presence of anthropogenic noise, such as highway traffic (Siemers and Schaub 2011).

In this study, the emission of creaks was changed in the presence of some types of vessel, which may indicate impacts in foraging efficiency, of concern given the frequent presence of ferries and the dolphin-watching boat in the dolphins' core habitat areas.

Significant changes were also observed for social calls: whistle characteristics shifted in frequency and duration, and in the presence of ferries and leisure boats, dolphins emitted whistles with higher start frequencies. The observed shifts in specific acoustic parameters of whistles may also be a vocal response that enables communication in such noisy contexts. Bottlenose dolphins are able to modify the emission ratio and the characteristics of whistles in order to avoid masking (Buckstaff 2004, Morisaka et al. 2005, May-Collado and Wartzok 2008). The use of higher frequencies has been reported as a masking avoidance response to low-frequency noise in several other species (Lesage et al. 1999, Brumm and Slabbekoorn 2005, Parks et al. 2007). Nevertheless, the reported changes may limit recognition of calls by the intended receiver (Weilgart 2007), and so it may disturb important social interactions such as mating or mother-calf communication.

This study suggests that the bottlenose dolphin residents in the Sado estuary may be moderately disturbed by the noise generated by boats in their habitat, and respond with some changes in their acoustic behavior. It was not possible to analyze differences according to habitat subarea because the animals already avoid the noisiest zones, near the Setúbal harbor, and sampling was therefore spatially biased.

The biological effects of observed changes in acoustic behavior are uncertain. Longterm implications of boat traffic must be considered and further investigated, as vessel noise may disrupt activities such as feeding or mating, and may affect residency patterns. 


\section{ACKNOWLEDGMENTS}

The authors would like to thank Tróia-Natura S.A. for financial support of the study. We also thank all the colleagues-Ana Rocha, Sofia Borges, Erica Cruz, Cecília Ferreira, Mafalda Freitas, Vera Mendão, Patrícia Rachinas-Lopes, and Erica Sá who helped in the field work. Joe Olson (CRT-Cetacean Research Technology) was a reliable source of helpful advice. Two anonymous reviewers contributed to improvements in the manuscript, and we are also grateful for support from the editors.

\section{Literature Cited}

Aguilar de Soto, N., M. Johnson, P. T. Madsen, P. L. Tyack, A. Bocconcelli and J. F. Borsani. 2006. Does intense ship noise disrupt foraging in deep-diving Cuvier's beaked whales (Ziphius cavirostris)? Marine Mammal Science 22:690-699.

Au, W. W. L. 1993. The sonar of dolphins. Springer Verlag, New York, NY.

Augusto, J. F., P. Rachinas-Lopes and M. E. dos Santos. 2012. Social structure of the declining resident community of common bottlenose dolphins in the Sado estuary, Portugal. Journal of the Marine Biological Association of the United Kingdom 92:1773-1782.

Brumm, H., and H. Slabbekoorn. 2005. Acoustic communication in noise. Pages 151-209 in P. J. B. Slater, C. T. Snowdon, T. J. Roper, H. J. Brockmann and M. Naguib, eds. Advances in the study of behavior. Academic Press, London, U.K.

Buckstaff, K. C. 2004. Effects of watercraft noise on the acoustic behavior of bottlenose dolphins, Tursiops truncatus, in Sarasota Bay, Florida. Marine Mammal Science 20: 709-725.

Deecke, V. B., J. K. B. Ford and P. J. B. Slater. 2005. The vocal behaviour of mammal-eating killer-whales: Communicating with costly calls. Animal Behaviour 69:395-405.

Dekeling, R., M. Tasker, M. Ainslie, M. Andersson, et al. 2013. Monitoring guidance for underwater noise in European seas. 2nd Report of the Technical Subgroup on Underwater Noise (TSG Noise). 12 pp. Available at http://meeting.helcom.fi/c/ document_library/get_file?p_l_id=1765910\&folderId=2258591\&name=DLFE-54221.pdf.

Dolman, S. J., P. G. H. Evans, G. Notarbartolo-di-Sciara and H. Frisch. 2011. Active sonar, beaked whales and European regional policy. Marine Pollution Bulletin 63:27-34.

dos Santos, M. E., S. Louro, M. N. Couchinho and C. Brito. 2005. Whistles of bottlenose dolphins (Tursiops truncatus) in the Sado Estuary, Portugal: Characteristics, production rates, and long-term contour stability. Aquatic Mammals 31:453-462.

dos Santos, M. E., M. N. Couchinho, A. R. Luís and E. J. Gonçalves. 2010. Monitoring underwater explosions in the habitat of resident bottlenose dolphins. The Journal of the Acoustical Society of America 128:3805-3808.

Foote, A. D., R. W. Osborne and A. R. Hoelzel. 2004. Whale-call response to masking boat noise. Nature 428:32816-32816.

Fuller, R. A., P. H. Warren and K. J. Gaston. 2007. Daytime noise predicts nocturnal singing in urban robins. Biology Letters 3:368-370.

Goldbogen, J., B. L. Southall, S. L. DeRuiter, et al. 2013. Blue whales respond to simulated mid-frequency military sonar. Proceedings of the Royal Society B: Biological Sciences 280:1-8.

Gravetter, F. J., and L. B. Wallnau. 2000. Statistics for the behavioral sciences. WadsworthCengage Learning, Belmont, CA.

Hastie, G. D., B. Wilson, L. H. Tufft and P. M. Thompson. 2003. Bottlenose dolphins increase breathing synchrony in response to boat traffic. Marine Mammal Science 19: 74-84.

Hatch, L. T., and A. J. Wright. 2007. A brief review of anthropogenic sound in the oceans. International Journal of Comparative Psychology 20:121-133. 
Herzing, D. L. 1996. Vocalizations and associated underwater behavior of free-ranging Atlantic spotted dolphins, Stenella frontalis and bottlenose dolphins, Tursiops truncatus. Aquatic Mammals 22:61-80.

Hildebrand, J. 2009. Anthropogenic and natural sources of ambient noise in the ocean. Marine Ecology Progress Series 395:5-20.

Holt, M. M., D. P. Noren, V. Veirs, C. K. Emmons and S. Veirs. 2009. Speaking up: Killer whales (Orcinus orca) increase their call amplitude in response to vessel noise. The Journal of the Acoustical Society of America 125:27-32.

IWC (International Whaling Commission). 2008. Report of the Scientific Committee. Journal of Cetacean Research and Management (Supplement) 10:1-406.

Janik, V. M., and P. M. Thompson. 1996. Changes in surfacing patterns of bottlenose dolphins in response to boat traffic. Marine Mammal Science 12:597-602.

Jensen, F. H., L. Bejder, M. Wahlberg, N. Aguilar Soto, M. Johnson and P. T. Madsen. 2009. Vessel noise effects on delphinid communication. Marine Ecology Progress Series 395:161-175.

Leeney, R. H., S. Berrow, D. McGrath, J. O’Brien, R. Cosgrove and B. J. Godley. 2007. Effects of pingers on the behaviour of bottlenose dolphins. Journal of the Marine Biological Association of the United Kingdom 87:129-133.

Lemon, M., T. P. Lynch, D. H. Cato and R. G. Harcourt. 2006. Response of travelling bottlenose dolphins (Tursiops aduncus) to experimental approaches by a powerboat in Jervis Bay, New South Wales, Australia. Biological Conservation 127:363-372.

Lesage, V., C. Barrette, M. C. S. Kingsley and B. Sjare. 1999. The effect of vessel noise on the vocal behavior of belugas in the St. Lawrence River estuary. Canada. Marine Mammal Science 15:65-84.

May-Collado, L. J., and D. Wartzok. 2008. A comparison of bottlenose dolphin whistles in the Atlantic ocean: Factors promoting whistle variation. Journal of Mammalogy 89:1229-1240.

Miller, P. J. O., M. P. Johnson and P. L. Tyack. 2004. Sperm whale behaviour indicates the use of echolocation click buzzes 'creaks' in prey capture. Proceedings of the Royal Society B: Biological Sciences 271:2239-2247.

Miller, L. J., M. Solangi and S. A. Kuczaj. 2008. Immediate response of Atlantic bottlenose dolphins to high-speed personal watercraft in the Mississippi Sound. Journal of the Marine Biological Association of the United Kingdom 88:1139-1143.

Morisaka, T., M. Shinohara and F. Nakahara. 2005. Geographic variations in the whistles among three Indo-Pacific bottlenose dolphin Tursiops aduncus populations in Japan. Fisheries Science 71:568-576.

Nowacek, D. P., L. H. Thorne, D. W. Johnston and P. L. Tyack. 2007. Responses of cetaceans to anthropogenic noise. Mammal Review 37:81-115.

Nowacek, S. M., R. S. Wells and A. R. Solow. 2001. Short-term effects of boat traffic on bottlenose dolphins Tursiops truncatus, in Sarasota Bay, Florida. Marine Mammal Science 17:673-688.

Papale, E., M. Azzolin and C. Giacoma. 2012. Vessel traffic affects bottlenose dolphin (Tursiops truncatus) behaviour in waters surrounding Lampedusa Island, south Italy. Journal of the Marine Biological Association of the United Kingdom 92:1877-1885.

Parks, S. E., C. W. Clark and P. L. Tyack. 2007. Short- and long-term changes in right whale calling behavior: The potential effects of noise on acoustic communication. The Journal of the Acoustical Society of America 122:3725-3731.

Popper, A. N., and A. Hawkins. 2012. The effects of noise on aquatic life. Springer, New York, NY.

Richardson, W. J., C. R. J. Greene, C. I. Malme and D. H. Thomson. 1995. Marine mammals and noise. Academic Press, London, U.K.

Scarpaci, C., S. W. Bigger, P. J. Corkeron and D. Nugegoda. 2000. Bottlenose dolphins (Tursiops truncatus) increase whistling in the presence of 'swim-with-dolphin' tour operations. Journal of Cetacean Research and Management 2:183-185. 
Siemers, B. M., and A. Schaub. 2011. Hunting at the highway: Traffic noise reduces foraging efficiency in acoustic predators. Proceedings of the Royal Society B: Biological Sciences 278:1646-1652.

Tasker, M., M. Amundin, M. André, A. Hawkins, et al. 2010. Marine Strategy Framework Directive G Task Group 11 Report. Underwater noise and other forms of energy (EUR 24341 EN G Joint Research Centre). Office for Official Publications of the European Communities, Luxembourg, Belgium. 55 pp. Available at http://ec.europa.eu/ environment/marine/pdf/10-Task-Group-11.pdf.

Tyack, P. L. 1998. Acoustic communication under the sea. Pages 163-220 in S. L. Hopp, M. J. Owren and C. S. Evans, eds. Animal acoustic communication. Springer, New York, NY.

Tyack, P. L. 2009. Acoustic playback experiments to study behavioral responses of freeranging marine animals to anthropogenic sound. Marine Ecology Progress Series 395:187-200.

Van der Graaf, A., M. A. Ainslie and M. Andre, et al. 2012. European Marine Strategy Framework Directive-Good Environmental Status (MSFD GES): Report of the Technical Subgroup on Underwater Noise and Other Forms of Energy. 75 pp. Available at http://ec.europa.eu/environment/marine/pdf/MSFD_reportTSG_Noise.pdf.

Van Parijs, S. M., and P. J. Corkeron. 2001. Boat traffic affects the acoustic behaviour of Pacific humpback dolphins, Sousa chinensis. Journal of the Marine Biological Association of the United Kingdom 81:1-6.

Weilgart, L. S. 2007. A brief review of known effects of noise on marine mammals. International Journal of Comparative Psychology 20:159-168.

Received: 16 August 2013

Accepted: 17 January 2014 